\title{
EDUCAÇÃO AMBIENTAL, CONSUMO E RESÍDUOS SÓLIDOS NA EDUCAÇÃO INFANTIL: O QUE DIZEM AS PESQUISAS DO GT 22 DA ANPED (2010-2015)
}

Natália Teixeira Ananias Freitas, Fátima Aparecida Dias Gomes Marin.

Universidade Estadual Paulista - UNESP, PPGE. Presidente Prudente, SP. E-mail: nathyteixeira@hotmail.com. Agencia Financiadora - CAPES

\section{RESUMO}

Este artigo apresenta os dados da pesquisa de Doutorado em andamento intitulada "Educação Ambiental, Consumo e Resíduos Sólidos no contexto da Educação Infantil: um diálogo necessário", pertencente ao PPGE - FCT/UNESP, Pres. Prudente. A motivação central da pesquisa é discutir a formação de professores e suas práticas pedagógicas diante da Educação Ambiental em Resíduos no contexto da Educação Infantil. A metodologia da pesquisa é baseada na abordagem qualitativa, do tipo "Survey". Nesta ocasião, enfatizamos os dados obtidos com o levantamento bibliográfico que considerou as publicações realizadas no período de 2010-2015 no GT 22 - Educação Ambiental, pertencente à ANPED, abordando as palavras-chave: Educação Ambiental, Consumo, Resíduos Sólidos e Educação Infantil. Os dados obtidos revelam a necessidade de ampliação e aprofundamento das pesquisas sobre Educação Ambiental que contemplem a formação de professores para atuarem na Educação Infantil.

Palavras-Chave: Consumo, Resíduos Sólidos, Educação Infantil, Educação Ambiental, Formação de Professores.

\section{ENVIRONMENTAL EDUCATION, CONSUMPTION AND SOLID WASTE IN EARLY CHILDHOOD EDUCATION: WHAT SAY THE RESEARCH OF THE GT 22 ANPED (2010-2015)}

\begin{abstract}
This article presents the PhD research data in progress entitled "Environmental Education, Consumption and Solid Waste in the context of early childhood education: a necessary dialogue", belonging to PPGE - FCT / UNESP, Pres. Prudent. The main motivation of the research is to discuss the training of teachers and their teaching practices on Environmental Education Waste in the context of early childhood education. The research methodology is based on a qualitative approach of the "Survey". On this occasion, we emphasize the data obtained from the literature that considered the publications made in the 2010-2015 period in GT 22 - Environmental Education, belonging to ANPED addressing keywords: Environmental Education, Consumption, Solid Waste and Early Childhood Education. The data reveal the need for broadening and deepening of the research on environmental education that include the training of teachers to Work In Early Childhood Education.
\end{abstract}

Keywords: Consumption, Solid Waste, Early Childhood Education, Environmental Education, Teacher Training. 


\section{INTRODUÇÃO}

Este artigo apresenta um recorte dos dados obtidos com a pesquisa de Doutorado em andamento intitulada "Educação Ambiental, consumo e Resíduos Sólidos no contexto da Educação Infantil: um diálogo necessário", pertencente ao Programa de Pós Graduação em Educação, FCT/UNESP, Presidente Prudente. Nossa motivação com a pesquisa é refletir sobre a formação de professores e suas práticas pedagógicas diante da Educação Ambiental em Resíduos no contexto da Educação Infantil. Pretende-se ainda, efetuar reflexões a respeito da formação inicial e continuada dos docentes que trabalham na Educação Infantil e investigar as suas práticas pedagógicas referentes ao tema Consumo e Resíduos Sólidos.

Os apontamentos metodológicos que serão utilizados no desenvolvimento da pesquisa dizem respeito a abordagem qualitativa, conforme Demo (2005) e Severino (2007) e como procedimento para a coleta de dados, os apontamentos da pesquisa do tipo "Survey", o que levará a realização de um amplo diagnóstico e análise de como acontece a Educação Ambiental na Educação Infantil no município de Presidente Prudente.

A maior parte dos professores das instituições de Educação Infantil não têm uma formação na área da Educação Ambiental para subsidiar as suas ações. Entretanto, é comum que os professores limitem as atividades realizadas com as crianças apenas a coleta de resíduos sólidos recicláveis. É importante que a criança compreenda todo o ciclo dos produtos, desde a extração da matéria prima até as consequências do descarte no meio ambiente, e não somente a respeito da reciclagem. A modificação de nossos posicionamentos a respeito do consumo e da produção de resíduos sólidos é essencial.

Nesse sentido, o papel do professor na Educação Infantil é o de contribuir para a formação das crianças com práticas educativas voltadas à compreensão da realidade local e global e o fomento de hábitos e atitudes responsáveis no que diz respeito ao meio ambiente.

Para aprofundarmos nossas discussões, este artigo apresenta os dados presentes no Banco de dados da Associação Nacional de Pós-Graduação e Pesquisa em Educação (ANPED), mais especificamente, as pesquisas presentes no Grupo de Trabalho 22 - Educação Ambiental (GT 22), considerando a temática da Educação Ambiental no contexto da Educação Infantil.

O objetivo deste trabalho é refletir sobre o que vem sendo apresentado ao longo dos últimos 5 anos (2010-2015) nas pesquisas vinculadas pela ANPED, GT 22, e qual a contribuição destas pesquisas para nossa investigação, ou seja, a Educação Ambiental, consumo e Resíduos Sólidos atrelada a Educação Infantil e formação de professores.

\section{METODOLOGIA}

A investigação em questão caracteriza-se pela abordagem qualitativa e os apontamentos da pesquisa do tipo "Survey". Elencamos esta técnica considerando os estudos de May (2004) e Babbie (1999), que relatam a utilização desse tipo de pesquisa para a obtenção de dados de uma numerosa amostra e de um levantamento amostral real.

A pesquisa está sendo realizada na Rede Municipal de Ensino de Presidente Prudente (SP), mais precisamente com os Coordenadores Pedagógicos da área de Educação Infantil da Secretaria Municipal de Educação (SEDUC) e com os docentes que atuam nas salas de Pré-Escola inseridas nas Escolas de Educação Infantil do município, visando a melhoria da qualidade dos trabalhos desenvolvidos durante a formação dos professores de Educação Infantil.

Os instrumentos de coleta de dados são os questionários com docentes que atuam em salas de pré-escola a respeito das concepções e práticas pedagógicas sobre Educação Ambiental, consumo e Resíduos Sólidos e entrevistas semi-estruturadas com os Coordenadores Pedagógicos da SEDUC para compreender a estrutura curricular proposta para a Educação Infantil do município e obter informações sobre a incidência da Educação Ambiental nas práticas das escolas. 
Com o intuito de fomentar nossa investigação de doutorado, apresentamos aqui o levantamento bibliográfico realizado no grupo de trabalho da ANPED, GT 22 - Educação Ambiental - a respeito da Educação Ambiental, Resíduos Sólidos e Consumo no contexto da Educação Infantil. Por meio de um recorte, delimitamos os dados correspondentes aos últimos 5 anos (2010-2015), verificando quais trabalhos poderiam colaborar com nossa investigação. Tomamos como critério para escolha dos materiais a leitura dos resumos e verificação das palavras-chave: Educação Ambiental; Resíduos Sólidos; Consumo; Educação Infantil.

O levantamento bibliográfico é o primeiro passo para uma investigação de qualidade, na medida em que, é por meio dele que se tem conhecimento do que vem sendo feito no campo acadêmico a respeito de um tema específico de pesquisa.

Galvão $(2010$, p. 1) afirma que

[...] realizar um levantamento bibliográfico é se potencializar intelectualmente com o conhecimento coletivo, para se ir além. É munir-se com condições cognitivas melhores, a fim de: evitar a duplicação de pesquisas, ou quando for de interesse, reaproveitar e replicar pesquisas em diferentes escalas e contextos; observar possíveis falhas nos estudos realizados; conhecer os recursos necessários para a construção de um estudo com características específicas; [...]

Considerando os apontamentos de Galvão (2010), é importante dar visibilidade ao que já vem sendo feito nas investigações de Mestrado e Doutorado a respeito da Educação Ambiental no contexto da Educação Infantil, bem como destacar as discussões realizadas no GT 22 da ANPED, que contemplam as principais pesquisas realizadas em âmbito nacional no contexto da Educação Ambiental.

Salientamos que esta pesquisa possui aprovação do Comitê de Ética em Pesquisa da FCT/UNESP, conforme parecer consubstanciado, CAAE: 52627515.1.0000.5402.

\section{RESULTADOS}

Por meio dos dados apresentados nos trabalhos vinculados ao GT 22 - Educação Ambiental da ANPED pode-se perceber que já existem estudos a respeito da Educação Ambiental e Resíduos Sólidos, Educação Ambiental e Educação Infantil, e Educação Ambiental e Consumo; porém, a respeito de nossa temática, que contempla Educação Ambiental, consumo e Resíduos Sólidos no contexto da Educação infantil não são apresentadas pesquisas, o que revela a necessidade de ampliação dessas discussões.

\section{DISCUSSÃO}

Enquanto seres pertencentes de um contexto social, estamos inseridos em uma Sociedade de Consumo, que adquire bens, consome materiais, produtos, serviços, recursos naturais e culturais e que atinge todas as faixas etárias. Cabe a nós refletirmos sobre o que estamos fazendo com relação a utilização abusiva dos recursos naturais, ao descarte e destino dos resíduos/lixo e aos impactos ambientais gerados desde a extração da matéria-prima até a decomposição dos resíduos/lixo no meio ambiente. Qual o reflexo do nosso modo de vida para as atuais e futuras gerações?

Portilho (2005) enfatiza que a Sociedade do consumo na qual fazemos parte e que é responsável na produção e comercialização de produtos e serviços para nossa subsistência colabora também para a disseminação de uma Cultura do Consumo, que induz os indivíduos a consumirem cada vez mais o que é disponibilizado pelo mercado. Dificilmente são realizadas reflexões sobre a origem dos produtos, a necessidade ou não de se possuir um determinado 
objeto, as matérias primas que compõem o objeto, a produção de resíduos sólidos e lixo ao final do processo e sobre o destino desses resíduos e os possíveis impactos ambientais decorrentes.

Os Resíduos Sólidos são o resultado do consumo exercido em sociedade, bem como as "sobras" de uma atividade humana diante do meio ambiente, numa perspectiva de ciclo, ou seja, os materiais que possuem possibilidade de retorno a cadeia produtiva. Para tanto, é necessário que esses resíduos sejam tratados e reaproveitados, evitando maiores danos ambientais. Nesse contexto, são pertinentes as ações que visem a redução do consumo de bens e materiais para que sejam produzidos cada vez menos resíduos sólidos.

No entanto, nem todos os resíduos sólidos podem ser tratados e reaproveitados, e são descartados em lixões, aterros controlados ou aterros sanitários, com a concepção de serem inservíveis, inúteis e insalubres ao contexto humano são, portanto, considerados lixos. Conforme os apontamentos de Sobarzo (2008, p.33), "[...] o lixo é considerado aquilo que sobrou de uma atividade qualquer e foi descartado sem que seus valores fossem preservados".

Torna-se necessário a discussão dessa temática com as crianças, principalmente as que estão no contexto da Educação Infantil, para que compreendam a diferenciação entre Resíduos Sólidos e Lixo e o que podem fazer para colaborar com a redução do consumo de materiais poluentes no seu contexto vivido.

É fundamental uma Educação Infantil que valorize o ambiente em que a criança está inserida e proporcione atividades e vivências que levem a aquisição de hábitos, valores, saberes e atitudes em prol das questões ambientais. Para tanto, é necessário também à formação de profissionais e professores da Educação Infantil que atendam a esta necessidade apontada pela sociedade em que vivemos, ou seja, um contexto social, político e educacional que requer mais atenção com relação ao meio ambiente.

Com o intuito de fomentar nossa discussão, apresentamos os dados referentes às últimas cinco Reuniões anuais realizadas pela Associação Nacional de Pós-Graduação e Pesquisa em Educação (ANPED), que comporta 24 grupos de Trabalho. De modo especial, apresentamos os dados referentes aos trabalhos completos aceitos e apresentados nas reuniões anuais realizadas dentro do período de 2010 - 2015, vinculados ao GT 22 - Educação Ambiental, considerando as palavras-chave: Educação Ambiental; Consumo; Resíduos Sólidos; Educação Infantil :

Quadro 01. Sistematização dos Trabalhos no GT 22, no período de 2010-2015

\begin{tabular}{|l|l|l|l|}
\hline $\begin{array}{l}\text { REUNIÃO } \\
\text { ANPED }\end{array}$ & $\begin{array}{l}\text { ANO DE } \\
\text { REALIZAÇÃO }\end{array}$ & TRABALHOS GT 22 & $\begin{array}{l}\text { TRABALHOS LIGADOS AO } \\
\text { TEMA DA PESQUISA }\end{array}$ \\
\hline 37a Reunião & 2015 & 13 & 4 \\
\hline 36a Reunião & 2013 & 7 & 1 \\
\hline 35a Reunião & 2012 & 17 & 4 \\
\hline 34a Reunião & 2011 & 18 & 2 \\
\hline 33a Reunião & 2010 & 21 & 2 \\
\hline
\end{tabular}

Em linhas gerais, percebe-se que os trabalhos aceitos no GT 22 apresentam uma pequena parcela de todos os Programas de Pós-Graduação ligados a temática ambiental existentes no Brasil. Encontramos trabalhos vinculados a Universidades e Faculdades localizadas no Rio de Janeiro, São Paulo, Rio Grande do Sul e Minas Gerais.

Foram encontrados os seguintes trabalhos no GT 22 - Educação Ambiental:

- 37ạ Reunião - 2015: SANTOS E FERREIRA (2015) - "Políticas e Documentos [MEC]: Há espaço para a relação criança/natureza na Educação Infantil?"; SALGADO (2015) "Discursos de Natureza em movimentos educacionais alternativos"; SAHEB (2015) - "Os sete saberes de Morin e sua contribuição para a formação de Educadores Ambientais"; 
GOMES (2015) - "A confluência da Educação Ambiental com a Educação Popular na alfabetização de adultos trabalhadores em cooperativa de Resíduos Sólidos".

- 36a Reunião - 2013: MUTZ (2013) - “A Educação Ambiental e o discurso do consumo consciente: uma análise sobre os modos como se produzem sujeitos consumidores nas pedagogias culturais contemporâneas";

- 35a Reunião - 2012: NOVICKI e PASSOS (2012) - "Técnico em meio ambiente e a Educação Ambiental: Campus Pinheiral do Instituto Federal de Educação, Ciência e Tecnologia do Rio de Janeiro"; QUEIROZ (2012) - "Caminhos para a inserção da dimensão socioambiental na formação inicial de educadores: Possibilidades e obstáculos encontrados"; OLIVEIRA (2012) - "Discutindo a práxis participativa: Concepções e contribuições à Educação Ambiental crítica da baixada fluminense"; COUTO (2012) - "Aprendizagem Social e formação humana no trabalho cooperativo de catadores(as) em São Paulo".

- 34ạ Reunião - 2011: TOLEDO( 2011) - "Quando vocês chegarem na escola, tem de passar e dar bom dia para a plantinha: um estudo sobre as relações e concepções de crianças com/sobre a natureza"; TOZONI-REIS, TEIXEIRA E MAIA (2011) - "As publicações acadêmicas e a Educação Ambiental na escola básica".

- 33a Reunião - 2010: LOGAREZZI (2010) - "Educação Ambiental em comunidades de aprendizagem: uma abordagem crítico-dialógica"; SANTOS (2010) - "Ações socioambientais em uma comunidade cooperada: trabalho e conflito como categorias centrais na prática educativa".

Considerando as pesquisas apresentadas no GT 22 da ANPED - Educação Ambiental, quando nos referimos a relação entre Educação Ambiental, Consumo e Resíduos Sólidos no contexto da Educação Infantil, é importante mencionarmos que são realizados estudos estabelecendo a relação da Educação Ambiental e Consumo e Educação Ambiental e Resíduos Sólidos, fato este que corrobora com a nossa investigação e aponta a grande importância do tema para o contexto educacional. No entanto, são poucas as investigações que priorizam em seus objetos de investigação as temáticas do Consumo e Resíduos Sólidos na Educação Ambiental, o que sinaliza a necessidade de realização de novas investigações que façam a integração desses temas.

\section{CONCLUSÃO}

O GT 22 - Educação Ambiental, vinculado à ANPED apresenta trabalhos significativos e que colaboram qualitativamente com nossa investigação. Contudo, especificamente a respeito da Formação de professores de Educação Infantil sobre Educação Ambiental, percebe-se ainda um pequeno número de trabalhos, o que requer com urgência a disseminação e aprofundamento das pesquisas nesse campo.

Compreendemos que ainda existem muitas lacunas no que tange a formação de professores para a Educação Infantil e quando estabelecemos relação da Educação Ambiental com a Educação Infantil, infelizmente encontramos poucas discussões e poucos documentos que subsidiam esse processo.

\section{REFERÊNCIAS}

BABBIE, E. Métodos de Pesquisas de Survey. Belo Horizonte: Ed UFMG, 1999, 519p.

COUTO, G.A. Aprendizagem social e formação humana no trabalho cooperativo de catadores(as) em São Paulo. In: REUNIÃO ANUAL DA ANPED, 35, 2012,Porto de Galinhas. Anais...Porto de Galinhas, ANPEd, 2012. Disponível em: <http://35reuniao.anped.org.br/trabalhos/135-gt22> DEMO, P. Metodologia da Investigação em Educação. Curitiba:IBPEX, 2005,186p. 
GALVÃO, M.C.B. O levantamento bibliográfico e a pesquisa científica. 2010. Disponível em: <http://www2.eerp.usp.br/Nepien/DisponibilizarArquivos/Levantamento_bibliografico_CristianeG alv.pdf >Acesso em: jan. 2016.

GOMES, D.de C. A confluência da Educação Ambiental com a Educação Popular na alfabetização de adultos trabalhadores em cooperativa de Resíduos Sólidos. In: REUNIÃO ANUAL DA ANPED, 37, 2015,Florianópolis. Anais...Florianópolis, ANPEd, 2015. Disponível em: <http://37reuniao.anped.org.br/trabalhos/>

LOGAREZZI, A.J.M. Educação Ambiental em comunidades de aprendizagem: uma abordagem crítico-dialógica. In: REUNIÃO ANUAL DA ANPED, 33, 2010,Caxambu. Anais...Caxambu, ANPEd, 2010. Disponível em: http://33reuniao.anped.org.br/internas/ver/trabalhos-gt22

MAY, T. Pesquisa Social: Questões, métodos e processos. Porto Alegre: Artmed, 2004.

MUTZ, A.S. da C. A Educação Ambiental e o discurso do consumo consciente: uma análise sobre os modos como se produzem sujeitos consumidores nas pedagogias culturais contemporâneas. In: REUNIÃO ANUAL DA ANPED, 36, 2013,Goiânia. Anais...Goiânia, ANPEd, 2013. Disponível em:< http://36reuniao.anped.org.br/trabalhos/180-trabalhos-gt22-educacao-ambiental>

NOVICKI,V. de A; PASSOS, S.R.M.M.S.dos. Técnico em meio ambiente e Educação Ambiental: campus Pinheiral do Instituto Federal de Educação, Ciência e Tecnologia do Rio de Janeiro (IFRJ). In: REUNIÃO ANUAL DA ANPED, 35, 2012,Porto de Galinhas. Anais...Porto de Galinhas, ANPEd, 2012. Disponível em: http://35reuniao.anped.org.br/trabalhos/135-gt22

OLIVEIRA, A. L de. Discutindo a práxis participativa: concepções e contribuições à Educação Ambiental crítica da Baixada Fluminense. In: REUNIÃO ANUAL DA ANPED, 35, 2012, Porto de Galinhas. Anais...Porto de Galinhas, ANPEd, 2012. Disponível em: <http://35reuniao.anped.org.br/trabalhos/135-gt22>

PORTILHO, F. Sustentabilidade Ambiental, consumo e cidadania. São Paulo: Cortez, 2005, 255p.

QUEIROZ, E.D. de. Caminhos para a inserção da dimensão socioambiental na formação de educadores: possibilidades e obstáculos encontrados. In: REUNIÃO ANUAL DA ANPED, 35, 2012,Porto de Galinhas. Anais...Porto de Galinhas, ANPEd, 2012. Disponível em: <http://35reuniao.anped.org.br/trabalhos/135-gt22>

SAHEB, D. Os sete saberes de Morin e sua contribuição para a formação de educadores ambientais. In: REUNIÃO ANUAL DA ANPED, 37, 2015,Florianópolis. Anais...Florianópolis, ANPEd, 2015. Disponível em:< http://37reuniao.anped.org.br/trabalhos/>

SALGADO, G.N. Discursos de Natureza em movimentos educacionais alternativos. In: REUNIÃO ANUAL DA ANPED, 37,2015, Florianópolis. Anais...Florianópolis, ANPED, 2015. Disponível em: <http://37reuniao.anped.org.br/wp-content/uploads/2015/02/Trabalho-GT22-3893.pdf>

SANTOS, A.M.M. Ações socioambientais em uma comunidade cooperada: trabalho e conflito como categorias centrais na prática educativa. In: REUNIÃO ANUAL DA ANPED, 33, 2010,Caxambu. -Anais... Caxambu, $2010 . \quad$ Disponível em: <http://33reuniao.anped.org.br/internas/ver/trabalhos-gt22> 
SANTOS, C.W.N; FERREIRA,V.S. Políticas e Documentos [MEC]: Há espaço para a relação criança/natureza na Educação Infantil? In: REUNIÃO ANUAL DA ANPED, 37, 2015, Florianópolis. Anais...Florianópolis, ANPEd, 2015. Disponível em:< http://37reuniao.anped.org.br/trabalhos/> SEVERINO, A.J. Metodologia do Trabalho Científico. São Paulo: Cortez Editora, 2007,304p.

SOBARZO, L.C.D. Resíduos Sólidos: Do conhecimento Científico ao Saber Curricular - a releitura do tema em livros didáticos de Geografia. 2008. Tese (Doutorado em Geografia). Faculdade de Ciências e Tecnologia, Universidade Estadual Paulista, Presidente Prudente - SP.

TOLEDO, M.L.P.B. de. "Quando vocês chegarem na escola, tem de passar e dar Bom Dia para a plantinha!" - Um estudo sobre as relações e concepções de crianças com/sobre a natureza. In: REUNIÃO ANUAL DA ANPED, 34, 2011,Natal. Anais...Natal, ANPEd, 2011. Disponível em: $<$ http://34reuniao.anped.org.br/index.php?option=com_content\&view=article\&id=135:trabalhosgt22-educacao-ambiental\&catid=47:trabalhos\&ltemid=59>

TOZONI-REIS, M.F.de C. (et al). As publicações acadêmicas e a Educação Ambiental na Escola Básica.In: REUNIÃO ANUAL DA ANPED, 34, 2011,Natal. Anais...Natal, ANPEd, 2011. Disponível em:<http://34reuniao.anped.org.br/index.php?option=com_content\&view=article\&id=135:trabal hos-gt22-educacao-ambiental\&catid=47:trabalhos\&ltemid=59> 